\title{
Forward Looking Equity Risk Premium: A Normative Long-Term View
}

\author{
Gregory Moscato \\ International University of Monaco, Les Moneghetti, Monaco \\ Email: gmoscato@monaco.edu
}

How to cite this paper: Moscato, G. (2019) Forward Looking Equity Risk Premium: A Normative Long-Term View. Theoretical Economics Letters, 9, 3021-3033. https://doi.org/10.4236/tel.2019.98186

Received: November 2, 2019

Accepted: December 23, 2019

Published: December 26, 2019

Copyright $\odot 2019$ by author(s) and Scientific Research Publishing Inc. This work is licensed under the Creative Commons Attribution International License (CC BY 4.0).

http://creativecommons.org/licenses/by/4.0/ (c) (i) Open Access

\begin{abstract}
We propose a Total Cash Flow present value model to estimate the implied risk premium equity indices typically used in financial models as proxies for the aggregate stock market. Following a bottom-up approach, we use individual companies' financial information as well as analysts' earnings estimates in order to reconstruct the index total cash flow and expected future cash flows. Using the prices for these indices, we then extract the implied Equity Risk Premia and analyze their evolution through time. To illustrate our approach, we run our model over a period of 10 years surrounding the 2008 financial crisis on five stock indices, namely the S \& P 500, the Euro Stoxx 50, the FTSE 100, the Hang Seng Index and the TOPIX 100. We find that our model is a conceptually robust approach to modeling long-term market Equity Risk Premia and provides a normative view of expected returns for practitioners.
\end{abstract}

\section{Keywords}

Equity Risk Premium, Discounted Cash Flows, Stock Market, Dividends, Share Buybacks

\section{Introduction}

Equity Risk Premia are playing a fundamental role in modeling risk and returns characteristics of traded equities. Equity Risk Premia are widely used by practitioners and by researchers for valuation purposes as well as for the estimation of firms' Cost of Equity Capital. Despite the central position of the Equity Risk Premium in many financial models, a consensus on the best way to estimate the Equity Risk Premium has not emerged. The main current methods used by researchers and practitioners follow very different logics, which in turn lead to large discrepancies of results. These discrepancies are far from being neutral as 
they lead in turn to substantial estimation errors when included in models such as in the capital asset pricing model. Ferson and Locke [1] have shown that the majority of errors in estimating the cost of capital could be traced back to risk premium estimates. It is therefore of great importance for researchers and practitioners to be able to rely on solid normative models for their estimate of Equity Risk Premia.

In this paper, we propose a model based on cash flows in order to extract the implied equity risk premium from various stock indices. We start by laying down the theoretical framework for Equity Risk Premia and their relationship with investors' perceptions and attitudes towards risk. We follow with a review of the main approaches pursued to measure Equity Risk Premia, and lay down the theoretical foundations behind cash flow based methods.

We then introduce our forward-looking multiple-stage cash flow model. We discuss the logic of each stage and the way they relate to our general theoretical frame. Next, we apply this model to recent financial data the obtained premia. We finally conclude with a discussion on the meaning of the resulting Equity Risk Premia and their potential ability to predict realized returns.

\section{ERP Models}

The main questions one should ask, when thinking about Equity Risk Premia, are why Equity Risk Premia matter and how the current main methods for estimating Equity Risk Premiago about to reflect the structure of the underlying economic reality.

Let us start with defining the equity risk premium: the Equity Risk Premium is the average extra return demanded by investors, on top of a risk free rate, as a compensation for investing in equity securities with average risk. We use the term "risk" in the classical sense of variance of returns around the mean expected return. Under this definition, a risk free return is a return with no possible variations. Damodaran [2], in his post crisis paper dedicated to Equity Risk Premia, recalls that the main classical risk and return models all agree on this distinction between risk free and risky assets. These models also assume that risk should be measured from the perspective of well-diversified investors, taking average risk and that only additional non-diversifiable risk should justify extra compensation.

The Equity Risk Premium is therefore added to the risk free rate in order to obtain the total expected return on an equity investment with average risk. Average risk here is to be understood as the risk for well-diversified investors and is typically measured as the market risk. The resulting market expected returns are then used for valuation purposes to discount expected cash flows with average risk. Various risk-return models, such as the Capital Asset Pricing Model, use the Market Equity Risk Premium to assess the returns that investors should expect from individual securities. By extension, such expected returns are used by practitioners as proxies for companies Cost of Equity Capital which is 
then incorporated to the discount rates used in capital budgeting processes.

Obviously, changes in Equity Risk Premia will have a direct influence on the pricing of equities as well as on the valuation of projects considered by companies. In a sense, Equity Risk Premia can be viewed as the price of risk. When investors perceive higher risk linked to future cash flows of an investment, they attribute a lower value to the cash flows attached to such risky investment. This lower value reflects investors' anticipation that the cash flows of the investment considered will exhibit a higher volatility, making the final outcome more uncertain.

Unlike for bonds, where required yields can easily be inferred from their current market prices and their future cash flows, bond cash flows being established contractually, Equities do not allow for such straightforward inferences. Indeed, the future cash flows of equity shares remain uncertain and provide no contractual guarantee. The consequence of such uncertainty is the lack of a general agreement on the best method to estimate the future expected returns implied by current prices, and by extension the Equity Risk Premium.

The academic literature has explored various methods, and an intense debate, on which approach to use and which one leads to the best estimates, continues within the finance community. While Campbel and Shiller suggested long run returns were "highly predictable" more recent research casted serious doubt on such claim. Ang and Bekaert [3] questioned the predictability of the ERP, while Goyal and Welch [4] found that overall none of the main methods provided any reliable out of sample prediction, with historical averages slightly outperforming most other approaches. These papers, and others tend to focus on the performance of existing models but one must realize these models have fundamental differences including in their theoretical logics and justifications. Yet, Duarte and Rosa [5], assuming that the combination of multiple forecasts can improve predictability, combine 20 existing models to estimate the historical one year forward ERP Their findings seem to imply an ERP above 10\% in 2012 and 2013. In our paper, we step away from a debate essentially focused on predictability and put an emphasis instead on developing a model grounded in solid theoretical foundations. Before presenting this model, we first review the main categories of methods that have been developed for the estimation of ERP and discuss their logics, their advantages and their limits.

We can sort the methods for estimating Equity Risk Premium into several categories:

\subsection{Historical Averages}

The use of historical data for estimating Equity Risk Premia is an easy and widely spread approach. Essentially, long-term average realized index returns are used with average realized returns on a governmental security (serving as proxy for risk free return). One big limitation of using historical data is that it only reflects realized returns, failing to capture expectations ex ante. Conceptually, such approach does not provide much explanation why past equity risk premia would 
predict future ones. Yet, despite this lack of theoretical justification, it seems that the historical track record for ERP exerts some influence on investors' expectations in a feedback mechanism. In particular, Goyal \& Welch [4] provide evidence that historical averages have better forecasting ability than most factor models. While others contend it may still be possible to develop better models, see for example Campbell and Thomson [6] who suggested that adjustments (in particular coefficient restrictions) on certain parameters were able to generate better forecasts than historical averages, although the improvements in predictability tend to remain marginal. An additional concern with the use of such averages lies in the choice of the periods over which to measure them. These choices in turn lead to large discrepancies in results, sometimes difficult to interpret. For example, following the financial crises that materialized since 2000, several major stock indices displayed negative Equity Risk Premia over periods ranging from 10 years to over 30 years (for Japanese equities that topped in 1988). These inconsistencies have encouraged the use of very long time series but the choice of a particular period remains ultimately very subjective.

\subsection{Surveys}

A second possible approach is to rely on surveys. One could survey analysts, professional and retail investors, corporate officers or even academics. One of the most extensive surveys by Fernandez et al. [7] reports the Equity Premia for 69 countries. This approach may appear as a rather straightforward manner to assess Premia demanded for a given market, provided such survey reflects accurately the aggregated market expectations. Yet, this approach proves to offer little improvement of predictability and suffers from some limitations: We can observe distortions of answers linked to the framing of the question and/or to the timing of the survey. In other words expected equity risk premium are the highest in bullish periods and the lowest following crises. Greenwood \& Shleifer [8] show in particular that there is a strong positive correlation of between historical returns and investors' expectations of future returns. One could suggest that such surveys will therefore suffer from similar issues than historical averages. In fact, the study of Greenwood \& Shleifer also underlines the negative correlation between investors' return expectation and realized returns. This poor predictive ability was already documented by Fisher \& Statman [9]. In their paper, the sentiment of several types of investors is compared and, while exhibiting differences, it did not provide with much insight about future returns.

Independently of any predictive (in) ability, such survey serves the purpose of measuring some aggregate sentiment, with no particular link to any objective criteria.

\subsection{Factor Models}

For the past century, factor models have been used to try to predict future performance of equities or realized Equity Risk Premia. Typical variables used include a variety of financial ratios such as earnings to price, book to market, divi- 
dend payout, as well as other financial measures such interest rates, default spreads, inflation rates, etc.

The vast choice of possible variables, time frame as well as regressions methods, such as time-series regressions or cross-sectional regressions, has led to the development of an abundant literature with often contradicting results. Many papers, let us point to some of the most influential ones, Campbel and Shiller [10], Fama and French [11], Lettau and Ludvigson [12], have been optimistic on the ability of such models to predict future returns. Goyal \& Welch [4] have pointed out that such optimism has encouraged the emergence of "a large theoretical and normative literature" leading to recommendations for the optimization of asset allocation based on these factors. Yet, in an updated version of previous work, Fama and French [13] do admit that their unconditional ERP model, based on dividend yield and earnings growth, is unable to provide a satisfactory description of historical realized returns. Much earlier on, Black [14] had already pointed out that the choice of specific factors often suffered from a lack of a theoretical justification and was more an exercise in data mining. In light of the overall predictive weaknesses of most models, Goyal \& Welch expressed serious doubts about the soundness of prescriptive recommendations based on factor models.

\subsection{Cash Flow Models}

A specific category of models aiming at assessing Equity Risk Premia is that of implied premium models. These models essentially rely on cash flow projections (for a given index) coupled with the underlying current prices of the index in order to extract the implied Equity Risk Premium.

Such models avoid looking backwards to estimate future returns as they are market driven and do not require per se to rely on historical data. What we like in such models is that they are quite flexible, can be used in any market, even with limited historical track record. Such models tend to be very explicit about their modeling of the future, unlike surveys where the logic and parameters used by respondents are generally unknown. In addition to these attractive features, cash flow models offer a conceptually robust description of the fundamental elements that are key to investment decisions: size of cash flows, growth and risk of those cash flows.

Very concretely, given a price and a series of cash flow one can infer the risk imbedded in the pricing. As market prices are observable, the primary difficulty is to properly model the expected future cash flows, which requires the ability to estimate potential growth of those cash flows far in the future. This is most likely the main difficulty faced by investors and academic alike when using such models: long-term growth rates are notoriously difficult to assess precisely. Yet robust estimates are particularly important for Discounted Cash Flow models: the sensitivity of the obtained premia to estimates of the average long-term growth of cash flows implies that small estimation errors in those long-term growth rates lead to large variations of implied Equity Risk Premia. The potential sub- 
jectivity of such estimates and the unlikeliness of homogeneous expectations among investors lead Pablo Fernandez [15] to claim that there cannot be an implied Equity Risk Premium at the market level. We clearly disagree with this claim and, like Fama \& French [16] and Damodaran [2], we do believe that it is possible to construct models that reflect and aggregate perspective on a market ERP. We present below an example of such model.

\section{A Forward Looking Equity Risk Premium Model}

In order to capture the Market Equity Risk Premium implied by a given pricing we developed a multiple stage discounted cash flow model. Our methodology aims at offering a forward-looking assessment of the long-term risk premium implied by the most current pricing of an equity index. We therefore take the view that long-term economic perspectives dominate the pricing of equity markets, especially at the aggregate market level and in major stock indices.

Let us recall that the Equity Risk Premium corresponds to the excess rate of return over the risk-free rate that is required by investors as compensation for the higher risk inherent to equities.

Equity Risk Premium $=$ Expected Return on Equities - Risk Free Rate.

Our model takes its roots in classical dividend discount models; While classical approach, relying on Miller and Modigliani (1961)'s irrelevance Theorem, assumed prices of equity shares should not be influenced by the actual payout, we took into account the observations of Mauboussin [17] concerning the growing importance of share buybacks over the past two decades. Mauboussin showed that in recent years, American companies as a whole paid out more earnings in the form of share buybacks than in cash dividends.

Furthermore, Damodaran [2] has rightfully pointed out that classical dividend discount models, by ignoring share buybacks, were in fact underestimating the actual rate of returns expected by investors. Furthermore, Boudoukh et al. [18] recall that a substantial amount of research has been using dividends and dividend yields to analyze pricing of these equity shares and their returns. They also advocate that all forms of distributed cash flows should be used and not just dividends. They further show the extent to which share buybacks as a percentage of total payout as grown, from $5 \%$ in the 1970 s to nearly $50 \%$ in early 2000 s, confirming previous studies, such as Fama and French [16], Grullon and Michaely [19], Dittmar and Dittmar [20] and Brav et al. [21], indicating a substitution of share buybacks for dividends, and suggesting that dividend and repurchase policies are not independent.

Taking into account those observations, we developed a multiple stage growth model of cash distributions for equity indices in which we add aggregate share buybacks to the aggregate dividends paid, allowing us to get a better measure of total cash flow to equity (CFE) for the index. Therefore, the present value of the index (reflected in its price) is equal to the sum of discounted total cash flows to equity. In its most simple form the corresponding formula is as follows: 


$$
\text { Value of Equity Index }=\sum_{t=1}^{N} \frac{E\left(C F E_{t}\right)}{\left(1+k_{e}\right)^{t}}+\frac{E\left(C F E_{N+1}\right)}{\left(k_{e}-g_{N}\right)\left(1+k_{e}\right)^{N}}
$$

In this equation, $E\left(C F E_{t}\right)$ is the expected aggregated cash flow to equity (potential dividends + share buybacks of the index) in year $t, k_{e}$ is the rate of return required by equity investors and $g_{N}$ is the stable growth rate (after year $N$ ).

$g_{N}$ corresponds to a long term sustainable growth rate.

Our model is however expanded in order to allow for different growth parameters.

More specifically, we model these expected cash flows through the following steps:

We start by computing the most recent CFE of the index. In order to do so, we pursue a bottom up approach. We retrieve the latest data of 12-month trailing dividends as well as 12-month trailing share buybacks for each individual company composing the chosen index. We aggregate our results to obtain the past 12-month CFE of the index.

In order to estimate future CFE we then estimate the potential growth of such CFE. We assume that the growth of cash flow distributed to investors is ultimately tied to the growth of earnings of those corporations. While individual and temporary deviations may arise and such short term swings in earnings may only be partly translated in changes of distributions, our combination of aggregated data from many companies and the long term perspective we take, allow us to affirm that, at the index level, the growth of distributions should not be able to deviate durably from earnings growth. Therefore, we can use earnings growth estimates to infer the growth of CFE.

We have defined three stages, with different earnings growth regimes. Those three stages are described below:

In stage 1 earnings growth, and therefore CFE growth, is based on analyst consensus expectations. Analyst pays a particular attention to these earnings estimates, more so than for dividend and share buybacks estimates as discussed by Wilcox [22]. Using this analyst consensus allows us to have robust estimation of short term CFE growth. Analysts however produce at most three years of forecasts; our first stage consequently only lasts three years. We have extracted those consensus earnings forecasts from Thomson Reuters Datastream. Using the 3 year analysts forecast of earnings growth, we compute the next 3 years of CFE.

One special case concerns the growth estimate of the first period. In times of great financial distress, it is possible to observe some breakdown in the relationship between actual cash flows distributed to investors and earnings reported. A common practice in publicly traded companies is to increase dividend payout in order to continue to provide investors with cash payment despite a low or negative earnings situation.

When such occurrence at the index level is identified, we use the one-year dividend consensus forecast to estimate the total cash flow in that period instead of relying on earnings growth estimates which are distorted by the excessive 
swing in earnings.

In our second stage, starting in year 44 until year t10, we assume CFE will continue to rise but that their growth will linearly converge towards the perpetual growth used from year t11 on. While it may be tempting to provide with specific estimates for each of the years in our second stage, the lack of specific data provides little ground to support, especially in the absence of analysts' estimates, the accuracy of such projections. We hence follow the practice described by financial textbooks [23] and assume that the growth of earnings and therefore of total cash flows will gradually converge toward a long-term sustainable growth rate.

Our third stage starts on the eleventh year. Since we cannot estimate forever our CFE, we introduce a terminal value of the index, modeled as a growing perpetuity.

$$
T V=\frac{E\left(C F E_{N+1}\right)}{\left(k_{e}-g_{N}\right)}
$$

We assume that the growth of the index CFE rise from the eleventh year on at a constant rate. This rate should reflect long-term economic growth and should therefore be tied to long-term earnings growth. In our model, this rate $g_{N}$ is proxied by the long term yields of treasuries (30-year rate) giving us a conservative perpetual growth parameter. Indeed the average yield of 30-year US treasury over the past 30 years on monthly data $(6.28 \%$ pa) is very close with long term average growth of the S \& P 500 earnings (from $5.98 \%$ to $6.17 \%$ for 30 -year and 50 -year average earnings' growth)

We provide below the formal formula for our 3-stage model:

$$
\begin{aligned}
& \text { Value of Equity Index } \text { 3stage model }^{3} \frac{\left(C F E_{t}\right)}{\left(1+k_{e}\right)^{t}}+\sum_{t=4}^{10} \frac{\left(C F E_{t-1} \times\left(1+\left(g_{t-1} \times \frac{\left(g_{3}-g_{T V}\right)}{8}\right)\right)\right)}{\left(1+k_{e}\right)^{t}}+\frac{\left(C F E_{10}\right) \times\left(1+g_{T V}\right)}{\left(k_{e}-g_{T V}\right)\left(1+k_{e}\right)^{10}}
\end{aligned}
$$

Once we have estimated the aggregated cash flows to the index for all three stages of the model, we implement a bottom up reconstruction of the index in order to obtain the total capitalization of that index. This bottom up approach gives us great flexibility to adapt our analysis framework to any existing index or any potential market proxy, including industry or sector subgroups. Once we have obtained the total market capitalization for our chosen index, we then use our multistage discounted cash flow model to infer the missing element: the discount rate. This discount rate acts as an internal rate of return (IRR) giving a unique solution. It can be interpreted as the implied required rate of return for that index and corresponds to the average investors' expectations for the index long-term rate of return. This is a very a similar logic to that of the Yield to Maturity for a bond. This Yield to Maturity represents the implied discount rate that allows the present value of all cash flows provided by the bond to match its current price.

In order to compute an expected implied Equity Risk Premium from that im- 
plied rate of return we must also chose an appropriate risk free rate. Indeed, Equity Premia correspond to the extra return obtained above a chosen risk free rate. We step away from the common practice, found many other empirical studies, of using monthly returns of treasury bills. As we take a long-term perspective on Equity Premia, we instead match our Premia with risk free rates linked to long-term maturity debt instruments. In our model we follow the duration matching solution ${ }^{1}$; concretely we specify a single risk free rate by choosing default-free securities (long term treasuries in our case) whose durations match most closely the durations of the indices analyzed. For those equity indices, the cash flows are modeled until infinity. To approximate the duration we can therefore use the duration formula for growing perpetuity: $\frac{1+k_{e}}{k_{e}-g}$

Using the average expected returns given by our model we obtain durations equal or above 20 years. In our search for best fit, we however do not pursue "perfect matching" through off-the-run securities in order to avoid liquidity issues and linked pricing distortions. In our analysis the best duration fit comes from the 30 year treasury bonds whose durations hover around 20 years, hence our choice of using 30 year Treasury bonds rate, when available for the markets analyzed, as a proxy for the risk free rate required to measure our Equity Risk Premium.

\section{Data and Results}

In order to provide some perspective of such model over a period including major swings in markets, including one of the most acute financial crisis since Second World War, we run an analysis over five major indices from 2003 until 2013. We use monthly data from January 2003 to December 2013 on five stock markets indices: S \& P500, Euro Stoxx 50, FTSE 100, Hang Seng Index and the TOPIX 100. All data have been extracted from Bloomberg.

Figure 1 displays the time varying Equity Risk Premium (ERP) for our five stock markets indices. Interestingly, our estimates vary significantly over our sample period and show different trends across indices.

In all indices, the period surrounding the financial crisis, from September 2009 until March 2009, shows significant increases in ERPs as prices collapse with most spiking around March 2009. It is most visible on the Hang Seng and TOPIX 100 where declines in stock market prices have been particularly sharp in the aftermath of the Lehman Brothers bankruptcy in October 2008. However, the ERP for the Japanese index continues to increase very strongly following March 2009 as prices of the TOPIX index continue to tumble until 2010.

Looking at the Euro Stoxx 50 and the FTSE 100, we see swings in the ERP during these months of crisis, reflecting the combination of the downward adjustments of analysts' future earnings expectations and the great volatility of prices.

${ }^{1}$ See Damodaran, A. [2] for a presentation of the duration matching approach. 


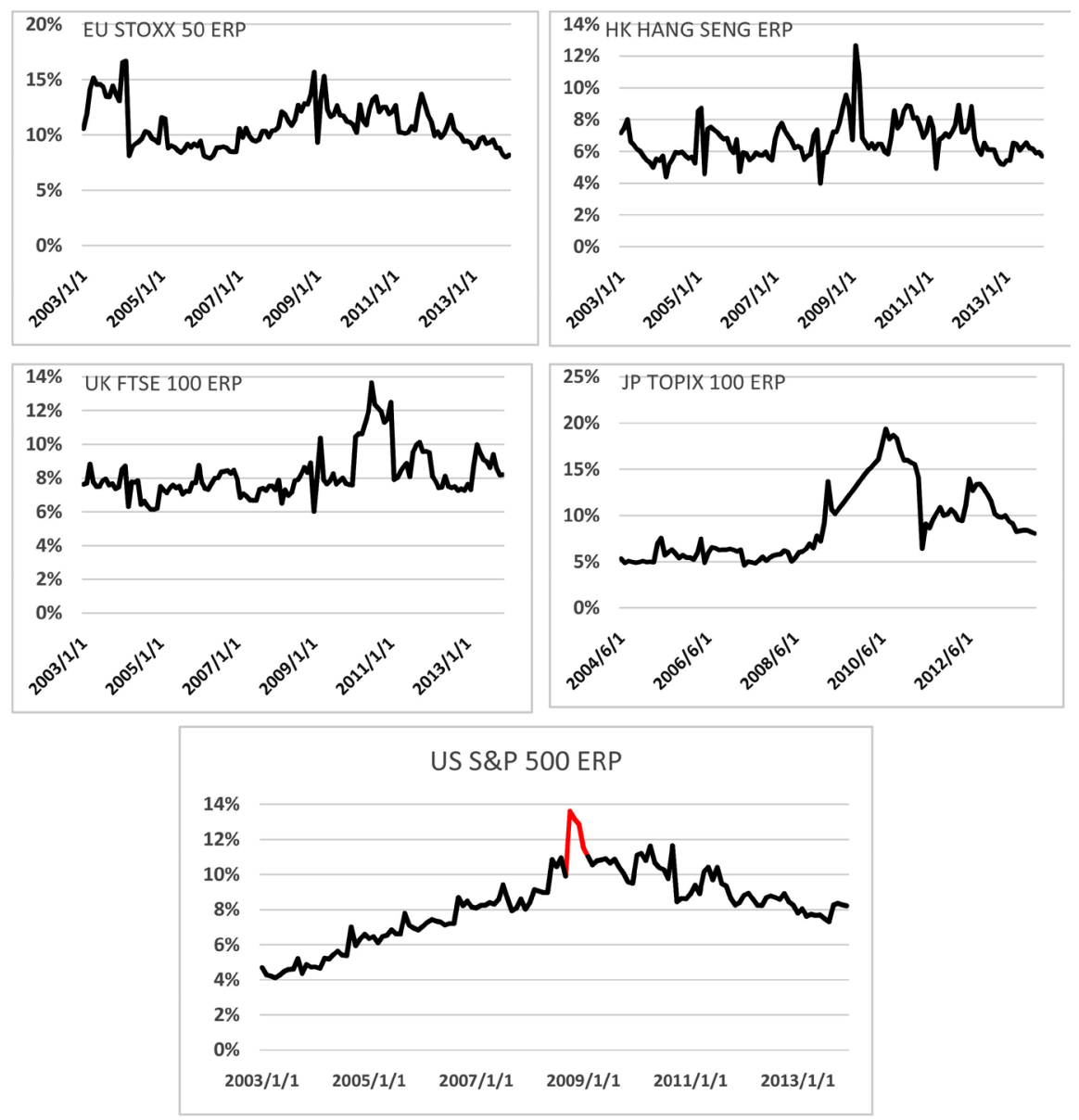

Figure 1. Equity risk premium for selected stock markets indices.

The US S\&P 500 estimates show a peculiar trend. The pattern of the US ERP shows a rather steady increase of the ERP in the five years leading to the crisis. What could be taken for a smooth transition in fact highlights a double trend: on the one hand a gradual increase in future expected earnings until 2008, on the other hand from the summer of 2007 until March 2009 a decline in stock prices. Once the prices start to recover from april 2009 on, the ERP initiates its descent towards the pre-crisis levels by the end of our sample.

Table 1 offers further visibility of the 5 indices ERPs for the period running from July 2007 until July 2009.

\section{Conclusions}

We conclude with a discussion on the meaning of the resulting Equity Risk Premia and their potential ability to predict realized returns.

We find that Cash flow based models are conceptually sounder than historical or survey based methods. Based on the sample analyzed, our results confirm that our total cash flow model is able to provide a robust description of an index' Equity Risk Premium. Major financial events are reflected in a coherent manner and it will be interesting to analyze this model's predictive ability on long-term 
Table 1. Indices equity risk premia around the financial crisis.

\begin{tabular}{|c|c|c|c|c|c|}
\hline Dates & S\&P 500 & EURO STOXX 50 & HANG SENG & FTSE 100 & TOPIX 100 \\
\hline $7 / 31 / 2007$ & $9.42 \%$ & $9.60 \%$ & $6.21 \%$ & $6.69 \%$ & $4.82 \%$ \\
\hline $8 / 31 / 2007$ & $8.64 \%$ & $10.36 \%$ & $6.34 \%$ & $7.33 \%$ & $5.14 \%$ \\
\hline $9 / 28 / 2007$ & $7.93 \%$ & $10.35 \%$ & $6.19 \%$ & $7.40 \%$ & $5.52 \%$ \\
\hline $10 / 31 / 2007$ & $8.08 \%$ & $9.80 \%$ & $5.47 \%$ & $7.27 \%$ & $5.10 \%$ \\
\hline $11 / 30 / 2007$ & $8.59 \%$ & $10.39 \%$ & $5.73 \%$ & $7.54 \%$ & $5.44 \%$ \\
\hline $12 / 31 / 2007$ & $8.02 \%$ & $10.41 \%$ & $5.82 \%$ & $7.53 \%$ & $5.66 \%$ \\
\hline $1 / 31 / 2008$ & $8.41 \%$ & $10.74 \%$ & $6.99 \%$ & $7.31 \%$ & $5.76 \%$ \\
\hline $2 / 29 / 2008$ & $9.13 \%$ & $12.11 \%$ & $7.37 \%$ & $7.89 \%$ & $5.81 \%$ \\
\hline $3 / 31 / 2008$ & $9.06 \%$ & $11.87 \%$ & $4.00 \%$ & $6.52 \%$ & $6.21 \%$ \\
\hline $4 / 30 / 2008$ & $8.98 \%$ & $11.25 \%$ & $5.92 \%$ & $7.30 \%$ & $6.00 \%$ \\
\hline $5 / 30 / 2008$ & $8.98 \%$ & $10.86 \%$ & $5.95 \%$ & $6.97 \%$ & $5.02 \%$ \\
\hline $6 / 30 / 2008$ & $10.84 \%$ & $11.35 \%$ & $6.55 \%$ & $7.14 \%$ & $5.42 \%$ \\
\hline $7 / 31 / 2008$ & $10.44 \%$ & $12.70 \%$ & $7.24 \%$ & $7.85 \%$ & $5.99 \%$ \\
\hline $8 / 29 / 2008$ & $10.93 \%$ & $12.15 \%$ & $7.22 \%$ & $7.90 \%$ & $6.09 \%$ \\
\hline $9 / 30 / 2008$ & $9.91 \%$ & $12.86 \%$ & $7.80 \%$ & $8.22 \%$ & $6.36 \%$ \\
\hline $10 / 31 / 2008$ & $13.62 \%$ & $12.77 \%$ & $8.74 \%$ & $8.64 \%$ & $6.94 \%$ \\
\hline $11 / 28 / 2008$ & $13.17 \%$ & $13.70 \%$ & $9.55 \%$ & $8.33 \%$ & $6.46 \%$ \\
\hline $12 / 31 / 2008$ & $12.87 \%$ & $15.69 \%$ & $8.77 \%$ & $8.91 \%$ & $7.81 \%$ \\
\hline $1 / 30 / 2009$ & $11.52 \%$ & $9.35 \%$ & $6.73 \%$ & $6.02 \%$ & $7.22 \%$ \\
\hline $2 / 27 / 2009$ & $11.03 \%$ & $13.18 \%$ & $12.67 \%$ & $8.09 \%$ & $9.16 \%$ \\
\hline $3 / 31 / 2009$ & $10.55 \%$ & $15.33 \%$ & $10.81 \%$ & $10.37 \%$ & $13.66 \%$ \\
\hline $4 / 30 / 2009$ & $10.78 \%$ & $12.33 \%$ & $6.85 \%$ & $7.89 \%$ & $10.62 \%$ \\
\hline $5 / 29 / 2009$ & $10.83 \%$ & $11.64 \%$ & $6.54 \%$ & $7.65 \%$ & $10.18 \%$ \\
\hline $6 / 30 / 2009$ & $10.90 \%$ & $11.86 \%$ & $6.20 \%$ & $7.84 \%$ & $10.69 \%$ \\
\hline $7 / 31 / 2009$ & $10.65 \%$ & $12.65 \%$ & $6.50 \%$ & $8.26 \%$ & $11.20 \%$ \\
\hline
\end{tabular}

data set. One should remember that the obtained Premia have a rather long-term perspective. In a similar manner that one would not assume that the Yield to Maturity of a long-term bond would offer accurate predictions of short-term price dynamics, one should not expect to use our model for short-term estimations of Stock markets behavior. While the chosen data set could not offer sufficient historical depth to provide some answers about longer-term dynamics, our position is that it should be unlikely that our model outperforms other measures proposed in the literature. Various models in the literature have attempted to produce Risk Premia that offer some predictability in and out of sample, yet the empirical performance of such predictions seems to remain statistically very weak, see Welch \& Goyal [4] for a comprehensive re- 
view of the performance of the most common variables used by previous studies. Cochrane [24] agrees in part with these results but he also reminds the reader that "If one really wants to forecast returns, additional variables are important, and one should pick variables and specifications that reflect repurchases, dividend smoothing, and possible changes in dividend payment behavior". Future analyses will confirm if this is indeed the case.

Yet, looking at our model, one must remember that our primary goal was for it to reflect properly the underlying structure of an index cash flow and their evolution. One of the biggest advantages of cash flow models is to provide explicit assumptions about cash flows and growth parameters, and to link these assumptions with a particular pricing. Despite this orientation, several components of the model rely on the quality of the pricing mechanism of stock and bond markets. The recent interventions from Central Banks over the past few years are potentially affecting the pricing mechanism in substantial ways, creating distortions in its ability to link properly certain factors, such as long-term rates, to long-term estimates of economic growth. The implied ERPs do not only reflect what the model predicts but what the market itself predicts through the pricing mechanism. It is therefore very dependent on the efficiency of the market pricing mechanism. In order for such pricing and the resulting implied discount rate to predict future returns, one still needs to assume that the market can assess the future. This assumption remains unsupported by evidence, so far.

\section{Conflicts of Interest}

The author declares no conflicts of interest regarding the publication of this paper.

\section{References}

[1] Ferson, W. and Locke, D. (1998) Estimating the Cost of Capital through Time: An Analysis of the Sources of Error. Management Science, 44, 485-500. https://doi.org/10.1287/mnsc.44.4.485

[2] Damodaran, A. (2009) Equity Risk Premiums (ERP): Determinants, Estimation and Implications-A Post-Crisis Update. Financial Markets, Institutions \& Instruments, 18, 289-370. https://doi.org/10.1111/j.1468-0416.2009.00151.x

[3] Ang, A. and Bekaert, G. (2007) Stock Return Predictability: Is It There? Review of Financial Studies, 20, 651-707. https://doi.org/10.1093/rfs/hhl021

[4] Goyal, A. and Welch, I. (2008) A Comprehensive Look at the Empirical Performance of Equity Premium Prediction. Review of Financial Studies, 21, 1455-1508. https://doi.org/10.1093/rfs/hhm014

[5] Duarte, F. and Rosa, C. (2015) The Equity Risk Premium: A Review of Models. Federal Reserve Bank of New York Staff Reports No. 714. https://doi.org/10.2139/ssrn.2646037

[6] Campbell, J. and Thompson, S. (2008) Predicting Excess Stock Returns out of Sample: Can Anything Beat the Historical Average? Review of Financial Studies, 21, 1509-1531. https://doi.org/10.1093/rfs/hhm055

[7] Fernandez, P., Martinez, M. and Fernández, A.I. (2019) Market Risk Premium and 
Risk-Free Rate Used for 69 Countries in 2019: A Survey. https://doi.org/10.2139/ssrn.3358901 https://ssrn.com/abstract $=3358901$

[8] Greenwood, R. and Shleifer, A. (2014) Expectations of Returns and Expected Returns. Review of Financial Studies, 27, 714-746. https://doi.org/10.1093/rfs/hht082

[9] Fisher, K. and Statman, M. (2000) Investor Sentiment and Stock Returns. Financial Analysts Journal, 56, 16-23. https://doi.org/10.2469/faj.v56.n2.2340

[10] Campbell, J. and Robert, S. (1988) The Dividend-Price Ratio and Expectations of Future Dividends and Discount Factors. Review of Financial Studies, 1, 195-228. https://doi.org/10.1093/rfs/1.3.195

[11] Fama, E. and French, K. (1992) The Cross-Section of Expected Stock Returns. Journal of Finance, 47, 427-465. https://doi.org/10.1111/j.1540-6261.1992.tb04398.x

[12] Lettau, M. and Ludvigson, S. (2001) Consumption, Aggregate Wealth, and Expected Stock Returns. Journal of Finance, 56, 815-849. https://doi.org/10.1111/0022-1082.00347

[13] Fama, E. and French, K. (2002) The Equity Premium. The Journal of Finance, 57, 637-659. https://doi.org/10.1111/1540-6261.00437

[14] Black, F. (1993) Estimating Expected Return. Financial Analysts Journal, 49, 36. https://doi.org/10.2469/faj.v49.n5.36

[15] Fernandez, P. (2019) Equity Premium: Historical, Expected, Required and Implied. https://ssrn.com/abstract $=933070$ https://doi.org/10.2139/ssrn.933070

[16] Fama, E.E. and French, K.R. (2001) Disappearing Dividends: Changing Characteristics or Lower Propensity to Pay? Journal of Financial Economics, 60, 3-43. https://doi.org/10.1016/S0304-405X(01)00038-1

[17] Mauboussin, M. (2006) Clear Thinking about Share Repurchase. "Mauboussin" on Strategy" Legg Mason Capital Management.

http://hurricanecapital.files.wordpress.com/2015/02/clear-thinking-about-share-rep urchase.pdf

[18] Boudoukh, J., Michaely, R., Richardson, M. and Roberts, M. (2007) On the Importance of Measuring Payout Yield: Implications for Empirical Asset Pricing. Journal of Finance, 62, 877-915. https://doi.org/10.1111/j.1540-6261.2007.01226.x

[19] Grullon, G. and Michaely, R. (2002) Dividends, Share Repurchases, and the Substitution Hypothesis. Journal of Finance, 57, 1649-1684.

https://doi.org/10.1111/1540-6261.00474

[20] Dittmar, A. andDittmar, R. (2002) Stock Repurchase Waves: An Explanation of the Trends in Aggregate Corporate Payout Policy. SSRN Electronic Journal. https://doi.org/10.2139/ssrn.346548

[21] Brav, A., Graham, J., Harvey, C. and Michaely, R. (2005) Payout Policy in the 21st Century. Journal of Financial Economics, 77, 483-527. https://doi.org/10.1016/j.jfineco.2004.07.004

[22] Wilcox, S. (2007) The Adjusted Earnings Yield. Financial Analysts Journal, 63, 54-68. https://doi.org/10.2469/faj.v63.n5.4840

[23] Bodie, Z., Kane, A. and Marcus, A. (2014) Investments. Global Edition, 10th Edition, McGraw Hill Higher Education, New York.

[24] Cochrane, J. (2008) The Dog That Did Not Bark: A Defense of Return Predictability. Review of Financial Studies, 21, 1533-1575. https://doi.org/10.1093/rfs/hhm046 